\title{
NEW SPECIES OF COCCIDAE FROM AUSTRALIA.
}

By E. Ernest Green, F.E.S., F.Z.S.

\section{Eriococcus serratilobis, sp. nov. (fig. 1).}

Ovisac white, strongly convex, broadly oval, narrower behind; very closely felted and tough. Length, 3.0 to $3.50 \mathrm{~mm}$. Breadth, 2.25 to $2.50 \mathrm{~mm}$.

Adult female broadly oval. Antenna (fig. 1, b) 6-jointed; 3rd joint longest; 6th almost equal to 3rd; antennal formula $3,6,2,(4,5)$. Legs well developed; tarsus as long as or longer than tibia ; tarsal digitules dilated and spatulate (fig. 1,c); ungual digitules hair-like, minutely knobbed. Claw with a minute denticle close to the point. Anal lobes (fig. 1, a) broad; irregularly conical ; densely chitinous ; the inner edge deeply serrate or pectinate throughout its whole length; bearing at the apex a longish slender spine followed by a long stout seta; two stout spines

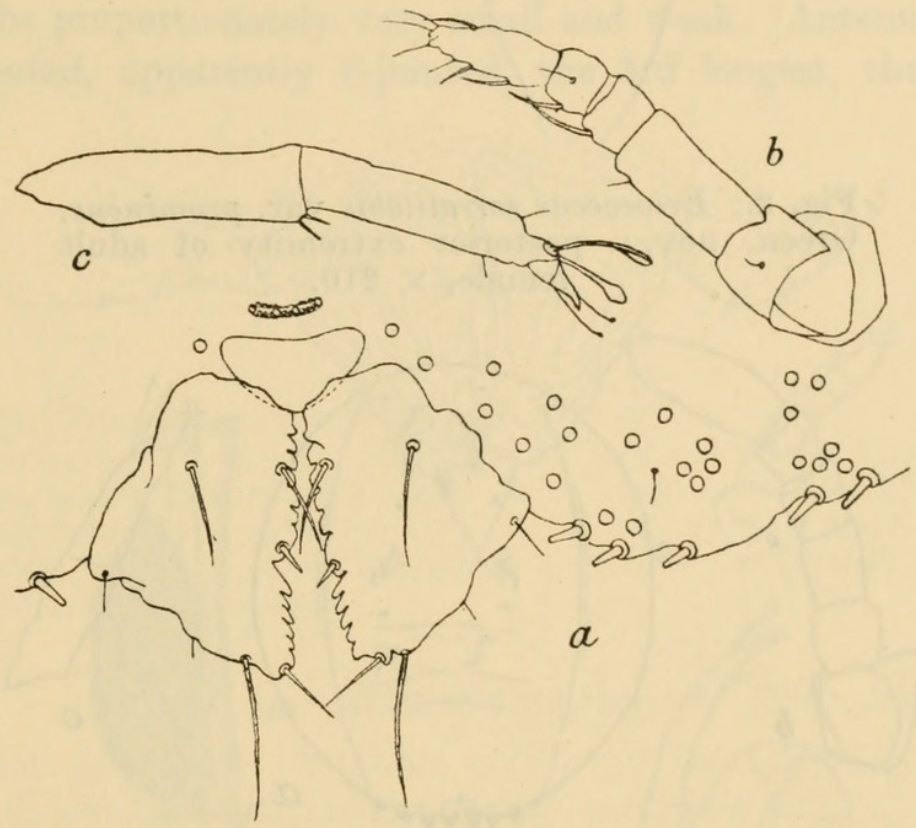

Fig. 1. Eriococcus serratilobis, Green, sp. n. ; $a$, posterior extremity of adult female, $\times 210$; $b$, antenna, $\times 210 ; c$, part of mid leg, $\times 210$.

on the inner edge and a setiform spine on the ventral face. There is a densely chitinous semicircular plate at the base of the lobes, situated dorsally. Margin of body with a complete series of truncate conical spines. No spines on other parts. Derm with numerous conspicuous circular pores, which are cup-shaped in profile. Length averaging $1.50 \mathrm{~mm}$. Breadth, $1.25 \mathrm{~mm}$.

Victoria: Mallee, on Eucalyptus gracilis (C. French, No. 142).

I would draw attention to the peculiar character of the digitules in this species. It is unusual to find dilated digitules in this genus, and it is still more unusual (if not unique) for the dilated members to be those of the tarsal joint. When one pair of digitules is dilated, it is almost invariably the unguals that display this character. 
Eriococcus serratilobis prominens, subsp. nov. (fig. 2).

Differs from typical serratilobis in the form of the anal lobes (see fig. 2), which are more prominent and cylindrical, scarcely broader at the base than at the truncate extremity, contrasting strongly with the shorter and broadly conical lobes of the type. The chitinous plate at the base of the anal lobes, in this form, is narrower and more lunate in shape.

Queensland: Townville, on undetermined plant (W. W. Froggatt, No. 363).

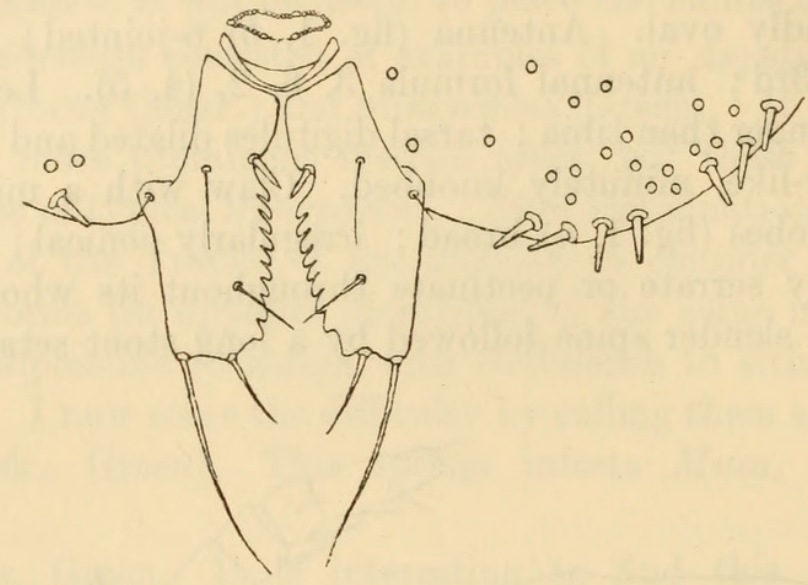

Fig. 2. Eriococcus serratilobis var. prominens, Green, nov.; posterior extremity of adult female, $\times 210$.
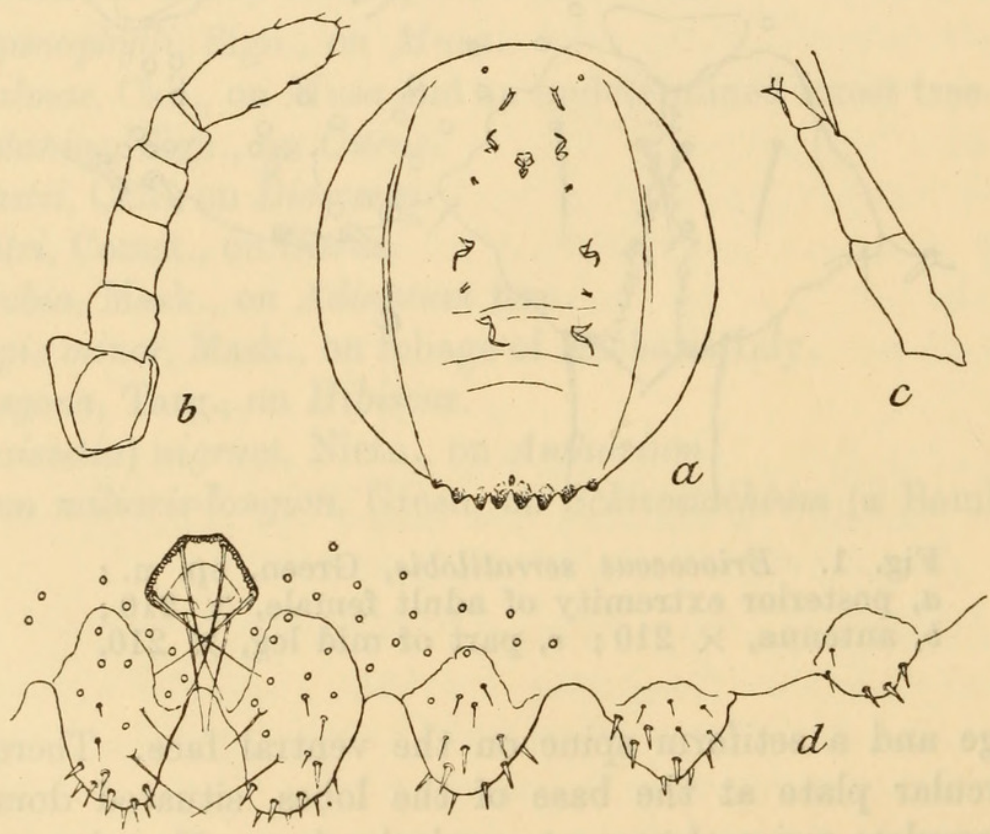

Fig. 3. Rhizococcus lobulatus, Green, sp. n.; a, adult female (under compression), $\times 13.5 ; b$, antenna, $\times 210$; $c$, part of mid leg, $\times 210 ; d$, posterior extremity of female, $\times 100$.

Rhizococcus lobulatus, sp. nov. (fig. 3).

Adult female dark reddish brown (dried examples); naked; broadly oval or subcircular, moderately convex, the segments well defined. Posterior extremity (fig. $3, a, d$ ) with eight prominent chitinous lobes, the median (anal) pair largest, 
the others decreasing in size to the outermost, which is always small and sometimes obsolescent. Each lobe surmounted by some rather slender, sharply pointed spines ; the anal pair with two longish slender setae on the inner side directed obliquely backwards. Derm with numerous small circular pores and some minute spiniform hairs. Anal ring with six slender setae. Antenna (fig. 3, b) 6-jointed, the 6th much the longest, 5th shortest, the remainder subequal. Limbs small but robust. Foot (fig. $3, c$ ) with a stout falcate claw ; tarsus equal in length to tibia. Length of complete insect 2.75 to $3.0 \mathrm{~mm}$. Breadth (under compression) 2.25 to $2.50 \mathrm{~mm}$.

New South Wales: Bramble Station, near Condobolin, on Acacia pendula (W. W. Froggatt No. 341).

Rhizococcus lecanioides, sp. nov. (fig. 4).

Adult female dark castaneous brown; naked; smooth, with some shallow foveae on the sides. Derm rigid and strongly chitinized, though clearing completely in potash; oval, narrower behind; strongly convex dorsally, concave below where the margins of the body clasp the branch upon which the insect rests (fig. 4, $a$ ). Antennae and limbs proportionately very small and weak. Antenna (fig. 4,c) very indistinctly segmented, apparently 6-jointed, the 3rd longest, the 1st incomplete

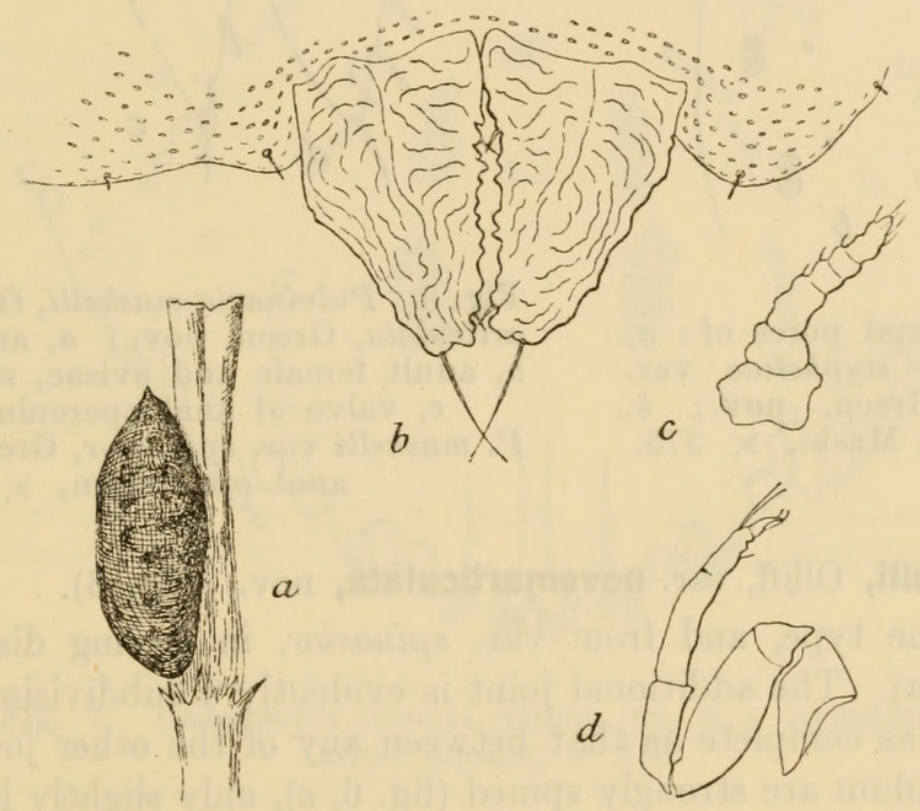

Fig. 4. Rhizococcus lecanioides, Green, sp. n. ; $a$, adult female, side view, $\times 11 ; b$, anal lobes, $\times 210 ; c$, antenna, $\times 210 ; d$, anterior leg, $\times 20$.

and of indefinite form. Tarsus unusually long, at least one-and-a-half times as long as the tibia (fig. 4, d), with a deep incision at about one-third of its length from the distal end, which gives the tarsus the appearance of being two-jointed. Anal lobes (fig. $4, b$ ) large, stout and prominent, densely chitinous and strongly wrinkled, with two small spines on the inner edge and a comparatively short stout seta at the extremity of each lobe. Derm without spines, but thickly set with small irregularly oval chitinous lenticels which appear to be arranged in roughly concentric series. Anal ring with eight stout setae. Length, 2.0 to $2.50 \mathrm{~mm}$.

Victoria : Sandringham, on slender twigs of Casuarina (C. French, No. 113, a). 
Asterolecanium stypheliae, Mask., var. multiporum, nov. (fig. 5).

Differs from the type in its larger size, and in the greater size and number of both paired and simple marginal pores (vide fig. 5, $a$ and $b$ ). In all other characters it agrees closely with the type. In typical stypheliae the simple pores accompanying the paired pores are in a single row-one simple to each paired pore (fig. $5, b$ ); in var. multiporum the simple pores are two or three deep (fig. 5, a). The puparium of typical stypheliae has an average length of $1.50 \mathrm{~mm}$., while that of var. multiporum measures $2 \cdot 25 \mathrm{~mm}$.

Victoria: Warmambool, on Samolus repens, Nov. 1914 (C. French, No. 168).

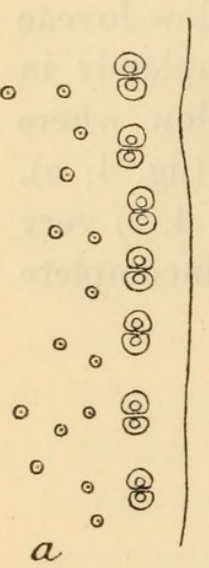

Fig. 5. Marginal pores of : $a$, Asterolecanium stypheliae var. multiporum, Green, nov.; $b$, A. stypheliae, Mask., $\times 375$.

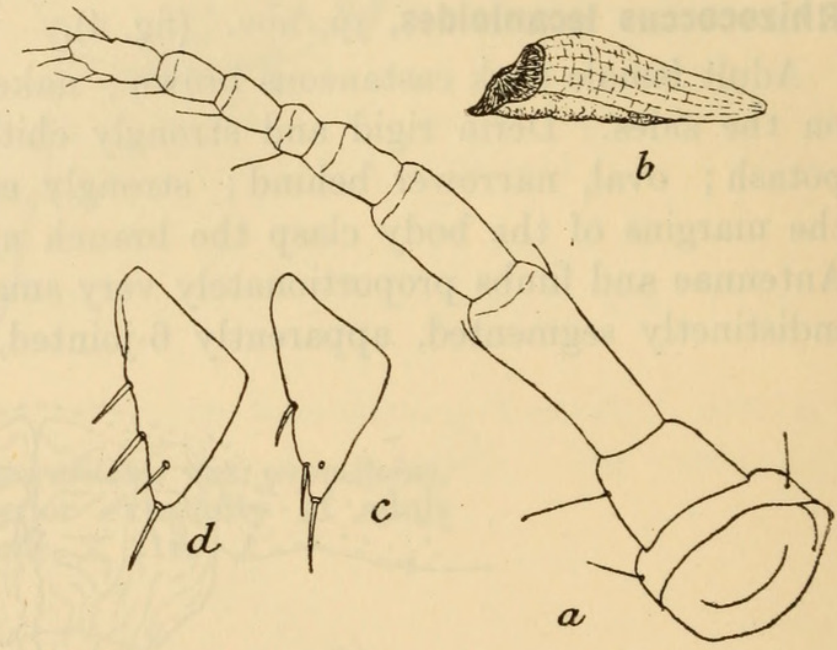

Fig. 6. Pulvinaria maskelli, Olliff, var. novem. articulata, Green, nov. ; $a$, antenna, $\times 210$; $b$, adult female and ovisac, side view, $\times 4$; $c$, valve of anal operculum, $\times 100$. $P$. maskelli var. spinosior, Green ; $d$, valve of anal operculum, $\times 100$.

Pulvinaria maskelli, Olliff, var. novemarticulata, nov. (fig. 6).

Differs from the type, and from var. spinosior, in having distinctly 9-jointed antennae (fig. 6,a). The additional joint is evidently a subdivision of the 5th, but the separation is as complete as that between any of the other joints. The valves of the anal operculum are strongly spined (fig. 6, c), only slightly less so than those of var. spinosior (fig. 6, $d$ ). The ovisac (fig. 6, $b$ ) is strongly convex and distinctly fluted longitudinally. The body of the insect is tilted upwards and rests on the anterior extremity of the ovisac. Total length of insect and ovisac, $7 \mathrm{~mm}$. Dimensions of adult female (under compression), 4.50 to $5.50 \mathrm{~mm}$. by 3.50 to $4.0 \mathrm{~mm}$.

Victoria: Mallee, massed on slender branches of Hymenanthera dentata (C. French No. 161).

Chionaspis frenchi, sp. nov. (fig. 7).

Female puparium white, pellicles reddish; broadest across the middle, rounded behind, moderately convex. Length, 2.50 to $2.75 \mathrm{~mm}$.

Male puparium white; flattish; very obscurely carinate. Length, $1.50 \mathrm{~mm}$. 
Adult female elongate, narrowed in front, broadest across the abdominal area; lateral margins of abdominal segments moderately protuberant. Pygidium (fig. 7) with two prominent, obscurely tricuspid median lobes, and a single small but prominent lateral lobe on each side, about half the breadth of the median lobes. The most conspicuous feature of the pygidium is the series of broad semilunar marginal pores, one between the median and lateral lobes and others, in pairs, at intervals along each side of the pygidium. Each of these marginal pores gives rise to a conspicuous broad flat plate, the free edge of which may be pointed, rounded, or obscurely serrate, and in the interval between the pairs is a complex marginal prominence, which appears to consist of narrow finger-like processes overlying: each other. Circumgenital glands in five groups; median group small, 2 to 4 pores: only; upper laterals, 12 to 16 ; lower laterals, 15 to 23 . Dorsal oval pores large and conspicuous, in interrupted series. Length, 1.25 to $1.75 \mathrm{~mm}$.

Length of nymphal pellicle, $0.75 \mathrm{~mm}$.

Victoria: Mallee, on Eucalyptus (C. French, Nos. 145 and 167).

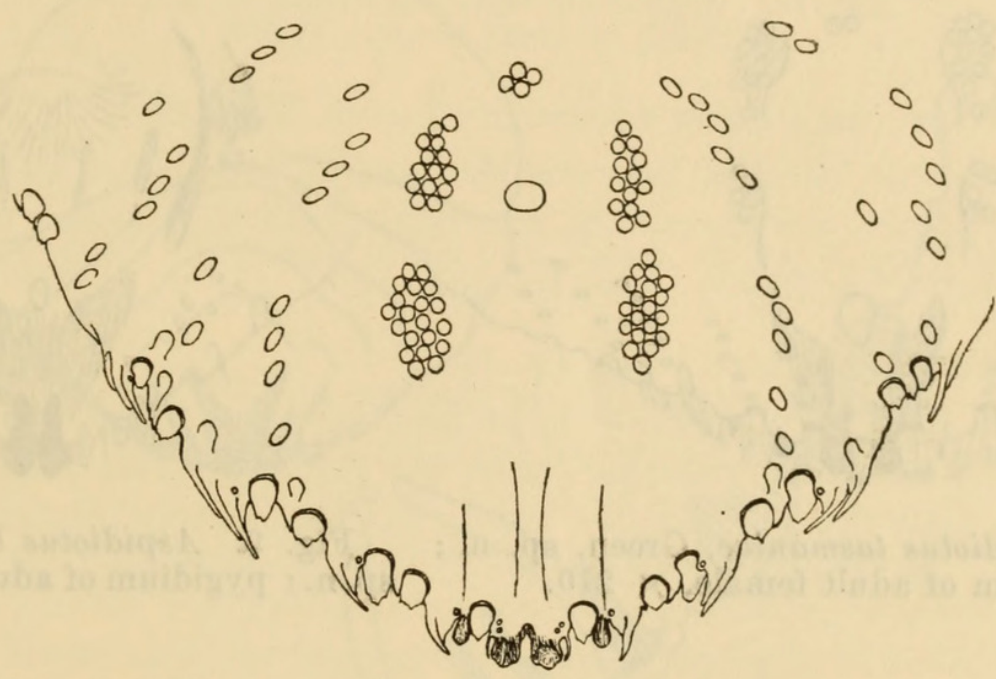

Fig. 7. Chionaspis frenchi, Green, sp. n.; pygidium of adult female, $\times 210$.

Chionaspis angusta, Green.

Froggatt has recently described, as Chionaspis eucalypti, a species which must be referred to my Ch. angusta, described in the Victoria Naturalist (xxi, p. 67) in 1904. I must myself accept the responsibility for this mistake, as Mr. Froggatt submitted his specimens to me for determination, and I failed to recognise them at the time. The examples on Eucalyptus are distinctly larger, and the puparia more dilated, than are the original specimens from Leptospermum; but the structural characters of the insect are typical.

Fresh material received from Mr. French (No. 74) show the typically narrow puparia, which are, in these examples, overlaid by a considerable quantity of loose flocculent white secretionary matter, disguising their true form.

(C155) 
Aspidiotus tasmaniae, sp. nov. (fig. 8).

Female puparium circular or broadly oval, moderately convex; opaque white or ochreous white. Exuviae exposed; subcentral; stramineous to fulvous. Diameter, $1.25 \mathrm{~mm}$.

Male puparium oblong oval; white; larval pellicle nearer one extremity. Length, $1.0 \mathrm{~mm}$.

Pygidium of adult female (fig. 8) with six lobes; the central pair large and prominent, obscurely tricuspid; the two outer pairs small, narrow and sharply pointed. Margin between median and inner lateral lobes rather deeply and broadly excised and thickened. There is a similar but narrower excision immediately behind each outer lateral lobe. Squames long and deeply fimbriate, the series extending beyond the outer lobes. Circumgenital glands in four or five groups, the medianwhen present-contains from 1 to 3 pores only; upper laterals 10 to 14 ; lower laterals 5 to 7 . Dorsal oval pores conspicuous, extending in linear series inwards from the margin. Body of insect subcircular. Length, $1 \mathrm{~mm}$.

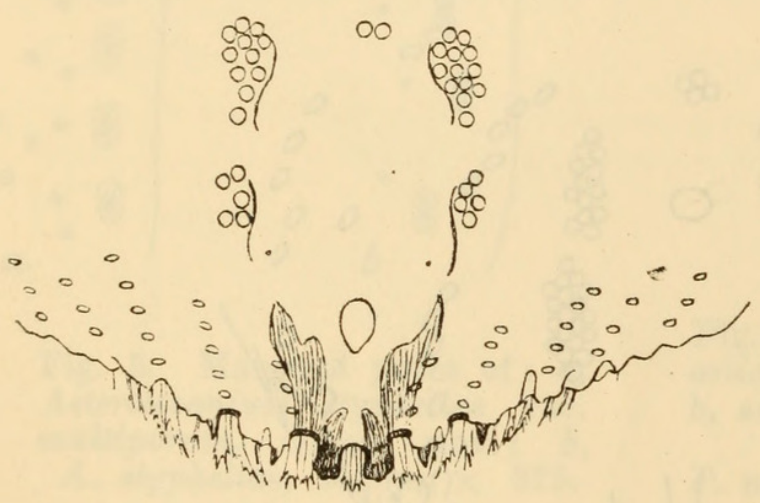

Fig. 8. Aspidiotus tasmaniae, Green, sp. n. ; pygidium of adult female, $\times 210$.

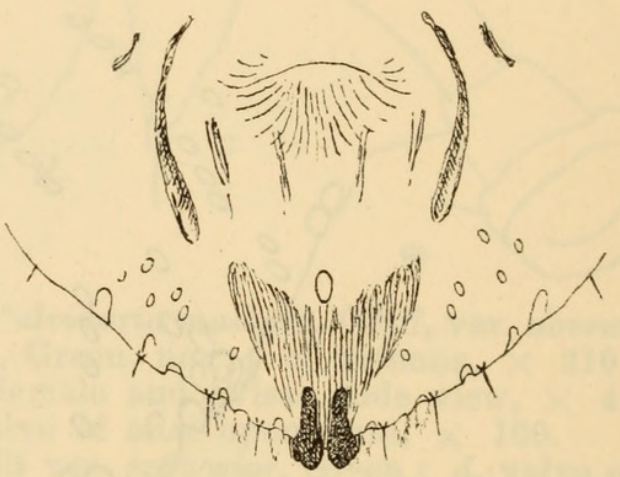

Fig. 9. Aspidiotus bidens, Green, sp. n.; pygidium of adult female, $\times 210$.

Nymphal pellicle broadly oval. Posterior extremity without definite lobes; with three shallow excisions on each side of the termen. Length, $0.65 \mathrm{~mm}$.

Tasmania: Launceston, on Ribes and Ampelopsis (F. M. Littler)

Victoria: On Eucalyptus, Acacia and Cytisus (C. French, Nos. 68, 148 and 165).

Aspidiotus (Hemiberlesia) bidens, sp. nov. (fig. 9.)

Female puparium dirty white; irregularly circular, moderately convex. Exuviae yellowish, eccentric. Diameter about $1.65 \mathrm{~mm}$.

Adult female broadly oval, somewhat sharply pointed at posterior extremity. Pygidium (fig. 9) with a single median pair of large and prominent lobes, slightly excised on the outer edge, their bases extending inwards. Marginal spines long. Pectinate squames very delicate and inconspicuous, apparently three on each side, discernible only by careful illumination. No circumgenital glands. Dorsal pores few. Anal aperture comparatively small. Length, $1.50 \mathrm{~mm}$.

Victoria: Lake Albacutya, on Casuarina (C. French, Nos. 115 and 122). 
Aspidiotus (Targionia) cedri, sp. nov. (fig. 10).

Female puparium circular, flattish; very dense; very dark blackish brown, inner surface sometimes whitish. Pellicles concealed, the position of the larval pellicle marked by a small raised boss. Diameter, 1.50 to $1.65 \mathrm{~mm}$.

Adult female (fig. 10, a) roughly circular. The pygidium-which occupies practically the whole of the abdominal area-broadly rounded, but deeply indented at the junctions of the suppressed segments. Posterior margin (fig. 10, $b$ ) with four broad, but only slightly prominent, obscurely tricuspid lobes, set close together, with thickened inward extensions. Beyond the lobes, on each side, the margin is strongly cristate, with three large and well-defined prominences which simulate lobes. On each side of the median lobes is a conspicuous translucent curved channel running inwards to the minute anal orifice. There are no circumgenital glands. Length, 1.25 to $1.50 \mathrm{~mm}$.

Queensland: on cedar logs (C. French, No. 111).

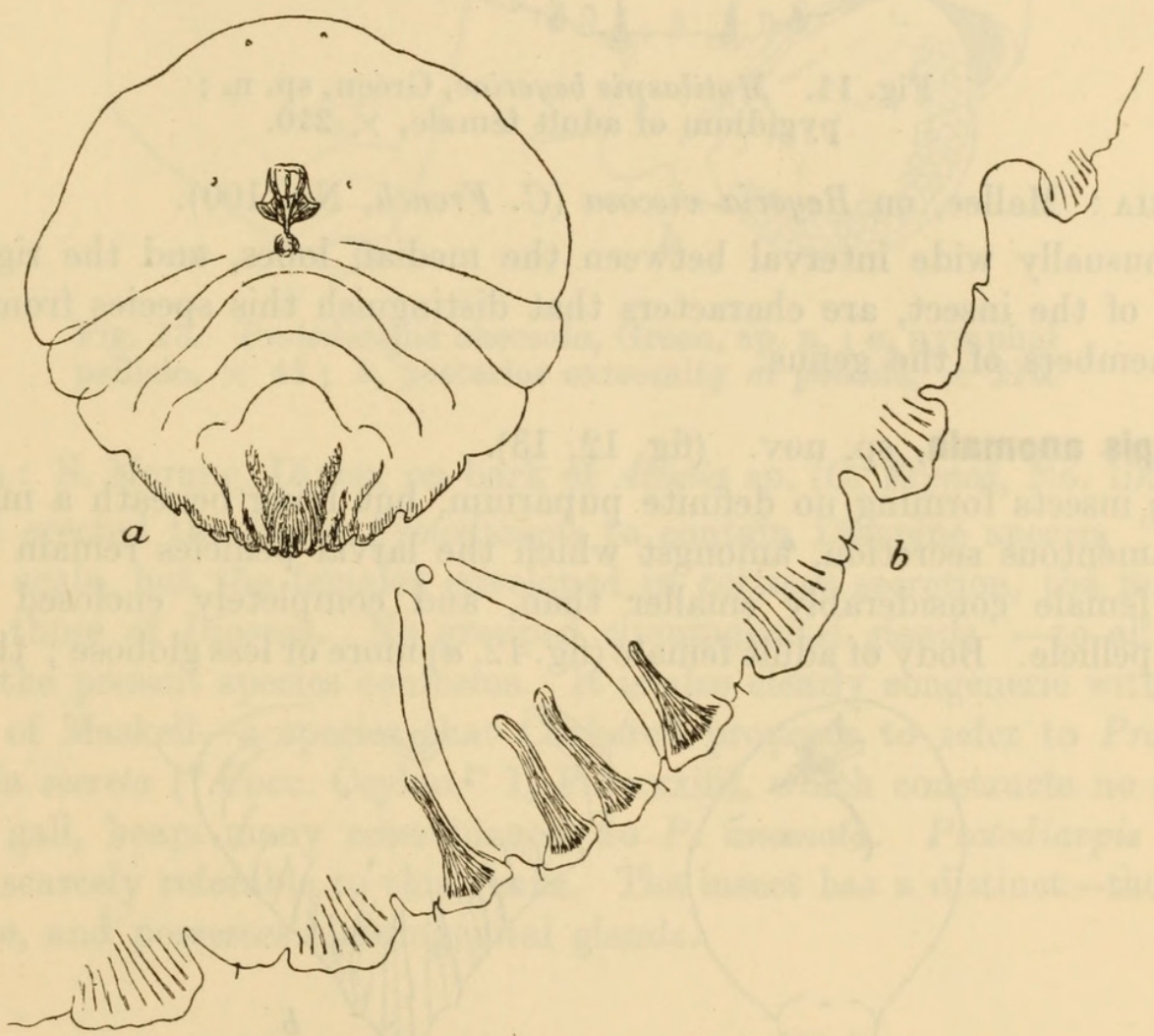

Fig. 10. Aspidiotus cedri, Green, sp. n. ; $a$, adult female, $\times 30$; $b$, posterior margin, $\times 210$.

Mytilaspis (Fernaldella) beyeriae, sp. nov. (fig. 11).

Female puparium opaque white, pellicles rufous or reddish ochreous; elongate, slightly broader across the middle, moderately convex; smooth. Length, $2.50 \mathrm{~mm}$. Breadth, $1 \mathrm{~mm}$.

Adult female elongate, broadest across the median area, posterior extremity evenly and broadly rounded. The derm of the whole insect is rigid and strongly chitinized, with no differentiation between the pygidium and the other parts of the 
body. Posterior margin with four small and rather narrow lobes (fig. 11), the median pair widely separate, the space between them being approximately twice as great as that between the median and lateral lobes. There are no tubular squames. Marginal spines very small. There is a deep marginal pore situated centrally between the median lobes, another between the median and lateral lobes, and others - usually in pairs - at points corresponding with the junctions of the suppressed segments. No circumgenital glands. Dorsal pores numerous, minute. Length, 1.50 to $1.75 \mathrm{~mm}$.

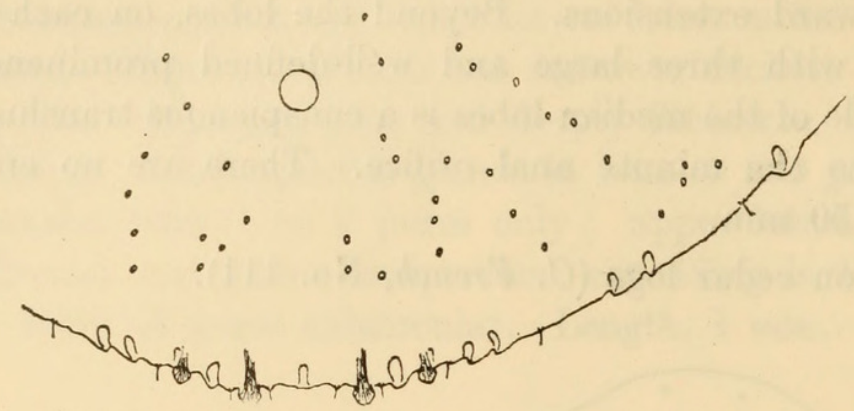

Fig. 11. Mytilaspis beyeriae, Green, sp. n. ; pygidium of adult female, $\times 210$.

Victoria: Mallee, on Beyeria viscosa (C. French, No. 100).

The unusually wide interval between the median lobes, and the rigid derm of the body of the insect, are characters that distinguish this species from any other known members of the genus.

Protodiaspis anomala, sp. nov. (fig. 12, 13).

Female insects forming no definite puparium, but lying beneath a mass of loose white filamentous secretion, amongst which the larval pellicles remain entangled.

Adult female considerably smaller than, and completely enclosed within the nymphal pellicle. Body of adult female (fig. 12,a) more or less globose ; the pygidium
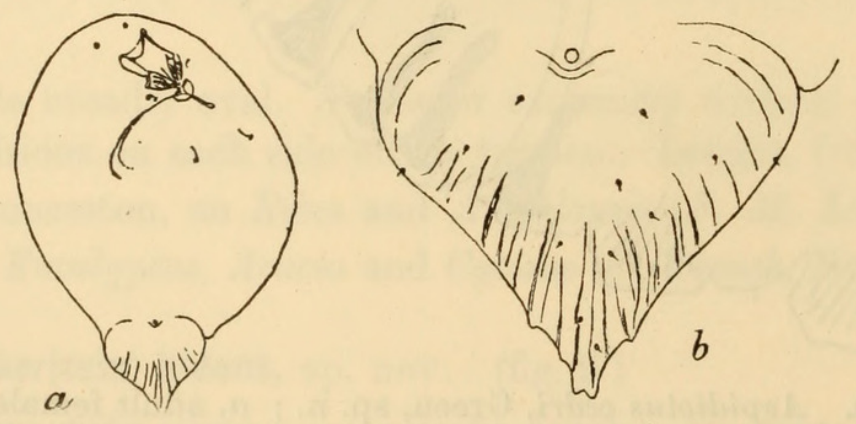

Fig. 12. Protodiaspis anomala, Green, sp. n. ; $a$, adult female, $\times 41 ; b$, pygidium of adult female, $\times 210$.

(fig. 12, b) flattened, cordate acuminate. There are no definite lobes, but there are one or two small irregular and asymmetrical marginal prominences on each side near the termen. Anal orifice small, situated quite at the base of the pygidium. No circumgenital glands. A few very small spines on the disk, and one marginal spine on each side, near the base. Many linear thickenings of the derm run inwards from the margin. Length, 0.50 to $0.75 \mathrm{~mm}$. 
Nymphal pellicle (fig. 13,a) globose and irregularly tumescent; densely chitinous, ochreous brown. The posterior extremity (fig. 13, $b$ ) bears a hinged semicircular plate covering a large aperture through which the larvae make their escape. The marginal area of this plate is marked with a polygonal cellular pattern. Length, 0.65 to $1.0 \mathrm{~mm}$.

Male puparium elongate, narrow, compact, flat; white ; uncarinated ; the larval pellicle ochreous, dehiscing circumferentially (as in the genus Aspidiotus), the two members being conspicuous at the anterior extremity, on the dorsal and ventral surfaces of the puparium respectively. Length, $1 \cdot 15 \mathrm{~mm}$.

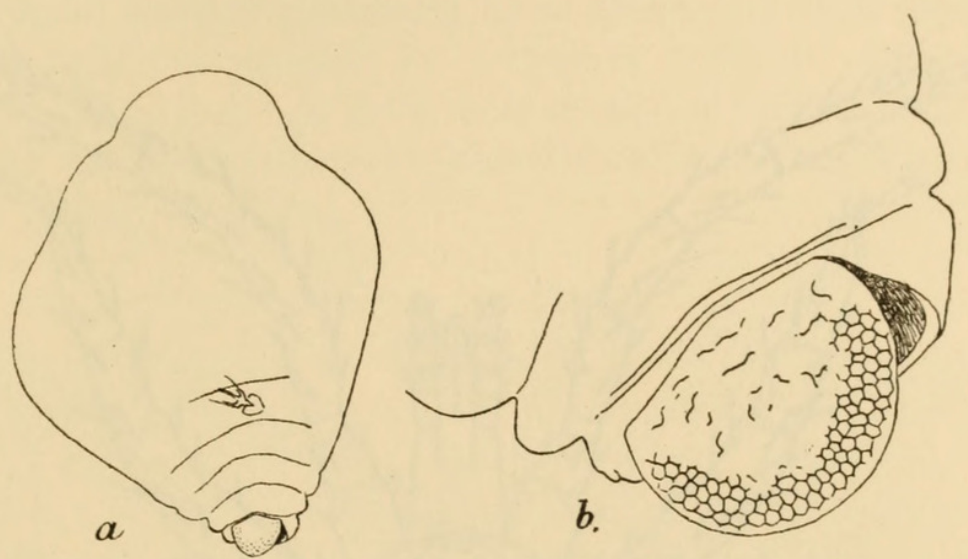

Fig. 13. Protodiaspis anomala, Green, sp. n.; $a$, nymphal pellicle, $\times 41 ; b$, posterior extremity of pellicle, $\times 210$.

Victoria : S. Morang, Dixon, on bark of Acacia sp. (C. French, No. 109).

Cockerell erected the genus Protodiaspis to contain Diaspine species "secreting no distinct scale, but the females enveloped in cottony secretion, the male pupae resembling those of Diaspis. No grouped circumgenital glands"-to all of which characters the present species conforms. It is also clearly congeneric with Fiorinia syncarpiae of Maskell-a species that Cockerell proposes to refer to Protodiaspis. My Fiorinia secreta ("Cocc. Ceylon," I, Pl. xxxiii), which constructs no scale, but inhabits a gall, bears many resemblances to $P$. anomala. Protodiaspis agrifoliae of Essig is scarcely referable to this genus. The insect has a distinct-though very small-scale, and possesses circumgenital glands. 


\section{$2 \mathrm{BHL}$ Biodiversity Heritage Library}

1915. "New species of Coccidae from Australia." Bulletin of entomological research 6, 45-53. https://doi.org/10.1017/S000748530004339X.

View This Item Online: https://www.biodiversitylibrary.org/item/110604

DOI: https://doi.org/10.1017/5000748530004339X

Permalink: https://www.biodiversitylibrary.org/partpdf/49430

\section{Holding Institution}

Smithsonian Libraries

\section{Sponsored by}

Biodiversity Heritage Library

\section{Copyright \& Reuse}

Copyright Status: Public domain. The BHL considers that this work is no longer under copyright protection.

This document was created from content at the Biodiversity Heritage Library, the world's largest open access digital library for biodiversity literature and archives. Visit BHL at https://www.biodiversitylibrary.org. 